\title{
Air ambulance transport
}

\author{
Eric Sy MD MPH, Terrance Ross MD
}

Cite as: CMAJ 2021 September 20;193:E1462. doi: 10.1503/cmaj.210354

\section{1 Air ambulances make access to care and health outcomes in rural communities more equitable}

In Ontario, air ambulances link remote First Nations communities to specialized hospital services, with 9.2 to 9.5 air transports per 100 on-reserve population annually, compared with 7.5 ground transports per 100 population for the whole province. ${ }^{1}$ Transportation by air ambulance has been shown to reduce the mortality rate from rural trauma in Nova Scotia compared with ground ambulances, ${ }^{2}$ and plays a crucial role in integrating health care services in remote Canadian communities.

\section{2}

\section{Team composition matters}

Adult trauma patients transported by air ambulance are more likely to survive when accompanied by nurses or paramedics with advanced critical care training compared with standard paramedic crews. ${ }^{3}$ In some provinces, air ambulance teams are supported by transport physicians with emergency medicine or critical care training who can accompany the patient. ${ }^{4}$

\section{3}

\section{Contraindications to transport include patient-related and}

\section{technical factors}

Patients who weigh more than $120 \mathrm{~kg}$ or are more than $69 \mathrm{~cm}$ wide may not meet aircraft and stretcher capacity requirements. ${ }^{5}$ Inclement weather limits the safe operation of air ambulances. Being in active cardiac arrest or active labour, having an untreated pneumothorax, or being aggressive or uncooperative may make a patient ineligible for air transport. Indications and contraindications are described in Appendix 1, available at www.cmaj.ca/lookup/doi/10.1503/cmaj.210354/tab -related-content.

\section{Faster is better, but speed is not the only consideration}

For time-sensitive situations, such as ST-segment elevation myocardial infarction, stroke and trauma, air transport has been associated with better outcomes and lower costs. ${ }^{2,6}$ However, providers should also consider travel distance, travel time and human resources (e.g., unstable patients transported by ground may need to be accompanied by the community's only physician or nurse), when determining transportation mode, in consultation with a transport physician.

\section{Pretransport preparation is important}

Providers should consider using a pretransport checklist, adapted to local needs (Appendix 1). Ornge provides a checklist (https://www.ornge.ca/ healthcare/transporting-a-patient), and the STARS website has resources on landing zone preparation (https://stars.ca/education-and-training/ landing-zone-training).

\section{References}

1. VanderBurgh D, Savage DW, Dubois S, et al. Epidemiologic features of medical emergencies in remote First Nations in northern Ontario: a cross-sectional descriptive study using air ambulance transport data. CMAJ Open 2020;8:E400-6.

2. Mitchell AD, Tallon JM, Sealy B. Air versus ground transport of major trauma patients to a tertiary trauma centre: a provincewide comparison using TRISS analysis. Can J Surg 2007;50: 129-33.

3. Laverty $\mathrm{C}$, Tien $\mathrm{H}$, Beckett $\mathrm{A}$, et al. Primary aeromedical retrieval crew composition: Do different teams impact clinical outcomes? A descriptive systematic review. Cal J Emerg Med 2020;22(Suppl 2):S89-103.

4. Powell DG, McCallum AL. Canadian transport medicine: waypoints and destinations. Can J Emerg Med 2020;22(Suppl 2):S1-3.

5. Transporting a patient. Mississauga (ON): Ornge; 2021. Available: https://www.ornge.ca/healthcare/transporting-a-patient (accessed 2021 May 25).

6. Taylor CB, Stevenson M, Jan S, et al. A systematic review of the costs and benefits of helicopter emergency medical services. Injury 2010;41:10-20.

Competing interests: Eric Sy is a STARS Air Ambulance Transport Physician. Terrance Ross is a STARS Air Ambulance Transport Physician and medical director of the STARS Regina base.

This article has been peer reviewed.

Affiliations: College of Medicine (Sy, Ross), University of Saskatchewan; Department of Critical Care (Sy), Saskatchewan Health Authority; Shock Trauma Air Rescue Service (STARS) (Sy, Ross); Department of Emergency Medicine (Ross), Saskatchewan Health Authority, Regina, Sask.

Content licence: This is an Open Access article dis tributed in accordance with the terms of the Creative Commons Attribution (CC BY-NC-ND 4.0) licence, which permits use, distribution and reproduction in any medium, provided that the original publication is properly cited, the use is noncommercial (i.e., research or educational use), and no modifications or adaptations are made. See: https://creativecommons. org/licenses/by-nc-nd/4.0/

Disclaimer: This article does not represent the views of the University of Saskatchewan, Saskatchewan Health Authority, and/or STARS.

Correspondence to: Eric Sy, ers728@usask.ca 